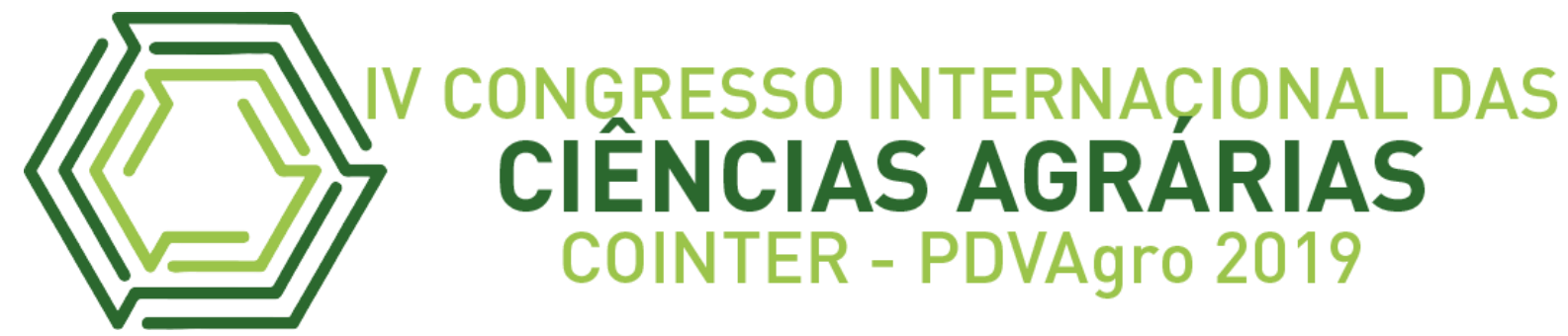

\title{
SAFRA E ENTRE SAFRA DO AÇAÍ: OS EFEITOS DESTE FENÔMENO NO COTI- DIANO DOS PRODUTORES DA ILHA DO COMBÚ, MUNICÍPIO DE BELÉM E SÃO SEBASTIÃO DA BOA VISTA
}

\author{
CULTIVO Y TEMPORADA BAJA DEL ACAI BERRY: LOS EFECTOS DE ESTE \\ PHENOMENON EN LA VIDA DIARIA DE LOS PRODUCERES DE LA ISLA \\ COMBÚ, MUNICÍPIO DE BELÉM Y SÃO SEBASTÃO DA BOA VISTA
}

\author{
CROP AND OFF-SEASON OF ACAI BERRY: THE EFFECTS OF THIS \\ PHENOMENON ON THE DAILY LIFE OF THE PRODUCERS OF THE COMBÚ \\ ISLAND, MUNICIPALITY OF BELÉM AND SÃO SEBASTIÃO DA BOA VISTA
}

\author{
Apresentação: Comunicação Oral \\ Inácia Do Vale Batista ${ }^{1}$, Maria Eliziane Pantoja da Silva ${ }^{2}$, Rodrigo Levy Dos Santos Saraiva ${ }^{3}$, \\ João Vítor Ferreira Da Silva ${ }^{4}$; Adriane da Costa Rocha ${ }^{5}$
}

DOI: https://doi.org/10.31692/2526-7701.IVCOINTERPDVAgro.2019.0040

\section{Resumo}

Este estudo tem por objetivo explorar as atividades alternativas que contribuem para renda e subsistência do povo ribeirinho do estado do Pará no período da safra e entressafra de açaí e fazer um comparativo da produção e preço de venda do fruto, observando os aspectos relevantes na Ilha do Combú no município de Belém e São Sebastião da Boa Vista no arquipélago do marajó. A metodologia empregada foi pesquisa bibliográfica seguida de visita a campo utilizando entrevista (método face to face) com formulário estruturado de perguntas abertas e fechadas aplicados a trinta produtores de cada localidade. Considerando resultados e comparações feitas em relação a produção e valor de venda do açaí, são notórias as dificuldades enfrentadas em ambos os locais no período de entressafra, especialmente em relação à rentabilidade que cai pela metade, e mesmo com o cultivo de outras culturas ou exercendo alguma atividade alternativa, ou ainda com auxílio de programas governamentais como muitos dos produtores e produtoras relataram ser beneficiados, essa déficit ainda não é suprido, ademais, os agricultores só vendem os produtos de outras culturas se houver excedentes, pois produzem apenas para sua subsistência. Constatou-se a disparidade do preço de venda do açaí pelo produtor entre os dois locais, sendo que a Ilha do Combú, por estar mais próxima do ponto de maior concentração de venda do fruto, não apresenta a figura do atravessador, enquanto em São Sebastião da Boa Vista, esta figura é frequente. Com isso conclui-se que existência de mediadores na comercialização do açaí interfere significativamente no lucro do produtor. Entende-se que a prática de manejo é simples, sem tanto conhecimento das técnicas adequadas, carecendo de incentivo e colaboração para maior produção e qualidade superiores do fruto de açaí.

Palavras-Chave: Agricultura Familiar, Sazonalidade, Ribeirinhos, Atividades Alternativas. 


\title{
Resumen
}

Este estudio tiene como objetivo explorar las actividades alternativas que contribuyen a los ingresos y la subsistencia de los ribereños del estado de Pará en el período de la cosecha y fuera de temporada de aaí y hacer una comparación con el precio de producción y venta de la fruta, observando los aspectos Rele-Vantes en la isla de Combú en el municipio de Belém y San Sebastián da Boa Vista en el archipiélago de Marajó. La metodología utilizada fue la investigación bibliográfica seguida de visitas de campo utilizando entrevistas (método Cara a Cara) con forma estructurada de preguntas abiertas y cerradas aplicadas a treinta productores en cada localidad. Teniendo en cuenta los resultados y las comparaciones realizadas en relación con la producción y el valor de venta de açaí, son notorias las dificultades enfrentadas en ambos lugares en el período fuera de temporada, especialmente en relación con la rentabilidad que cae a la mitad, e incluso con el cultivo de otras culturas o el ejercicio de alguna actividad alternativa, o con la ayuda de programas gubernamentales como muchos de los productores y productores han informado de ser beneficiados, este déficit aún no se procata, además, los agricultores sólo venden los productos de tros cultivos si hay excedentes, porque producen sólo para su subsistencia. Se encontró la disparidad del precio de venta del aaí por el pro-dutor entre los dos sitios, y la isla de Combú, porque está más cerca del punto de la mayor concentración de la venta de frutas, no presenta la figura del Traverador, mientras que en San Sebastián da Boa Vista , esta cifra es frecuente. Esto concluye que la existencia de mediadores en la comercialización de la baya de açai interfiere significativamente en el beneficio del productor. Es probable que la práctica de gestión sea sencilla, sin tanto conocimiento de las técnicas adecuadas, carente de estímulo y colaboración para una mayor producción y calidad superior del fruto del açaí.

Palabras Clave: Agricultura familiar, estacionalidad, Bordeando, actividades alternativas.

\begin{abstract}
This study aims to explore the alternative activities that contribute to income and subsistence of the riverside people of the state of Pará in the period of the harvest and off-season of açaí and make a comparative of the production and sale price of the fruit, observing the relevant aspects in the island of Combú in the municipality of Belém and São Sebastião da Boa Vista in the archipelago of Marajó. The methodology used was bibliographic research followed by field visits using interview (Face to Face method) with structured form of open and closed questions applied to thirty producers in each locality. Considering results and comparations made in relation to the production and value of sale of açaí, it's notorious the difficulties facing in both locations in the off-season period, especially in relation to the rentability that falls in half, and even with the cultivation of other cultures or exercising some alternative activity, or with the aid of governmental programs as many of the producers and growers have reported to be benefited, this deficit is not yet provison, moreover, farmers only sell the products of Other crops if there are surpluses, because they produce only for their subsistence. It was found the disparity of the sale price of açaí by the producer between the two sites, and the island of Combú, because it is closest to the point of the highest concentration of the fruit sale, does not present the figure of the middleman, while in São Sebastião da Boa Vista , this figure is frequent. This concludes that the existence of mediators in the commercialization of Acai berry interferes significantly in the producer's profit. It is likely that the management practice is simple, without
\end{abstract}


so much knowledge of the appropriate techniques, lacking encouragement and collaboration for higher production and superior quality of the fruit of açaí.

Keywords: Family farming, seasonality, Riverside, alternative activities.

\section{Introdução}

O açaí, Euterpe oleraceae Mart. pode ser apontado como a palmeira de maior importância cultural, econômica e social na Região Norte, sendo encontrado ao longo dos rios, igarapés, baixadas e áreas muito úmidas. Estudos de mercado apontam que o aumento da demanda de polpa do fruto do açaí é crescente, tornando essa espécie uma alternativa para o desenvolvimento e melhoria de vida do meio rural. (NÓBREGA; LIMA; NETO. 2013).

O Estado do Pará destaca-se no cenário nacional como maior produtor de açaí, em 2013, a participação desse estado na produção brasileira de açaí fruto foi de 85,6\%, os sistemas de produção extrativos tradicionais e extrativo manejado representam 79,28\%. O processo de expansão da produção do açaí-fruto está beneficiando os produtores extrativistas e os consumidores, assim como contribuindo para eliminar os impactos ambientais da extração predatória do palmito, que passa a ser extraído apenas das plantas improdutivas das áreas de plantios e de manejo. (NOGUEIRA; SANTANA. 2016)

Antes da expansão da demanda de frutos do açaizeiro, a extração tinha por objetivo o consumo doméstico, com pouca venda de excedente, associado à produção de alimentos: arroz (Oryza sativa), mandioca (Manihot esculenta), captura de peixes e camarões. A valorização do fruto teve efeito positivo sobre a conservação de açaizais nativos (HOMMA, et al. 2006).

Para Silva et al., (2015), a atividade de extração do açaí é uma fonte de renda importante para as famílias interioranas, sendo dependentes de tal atividade, já que uma boa parcela de sua renda está diretamente ligada à venda do açaí. Um grande problema é a falta de planejamento fixo e estruturado para os períodos de baixa produtividade.

Sabe-se que no período de entressafra do açaí, o agricultor busca outras formas de produção para sua subsistência e fonte de renda. Essa dinâmica dispõe de uma atenção maior para se compreender que a agricultura não é simplesmente um sistema de produção de alimentos, mas sim, um sistema complexo que envolve o ser humano, seu trabalho e ambiente (NÓBREGA; LIMA; NETO. 2013).

Desse modo, a presente pesquisa pode contribuir para a área acadêmica servindo como base para trabalhos posteriores, além de levar tais informações a sociedade. Considerando que pesquisas acerca dessa temática ainda não foram realizadas, o trabalho consistirá em fornecer 
dados para venturos pesquisadores, na melhoria das formas de manejo e incremento das atividades numa perspectiva de aperfeiçoamento na produção. Nesse contexto, o objetivo da pesquisa é o levantamento dos dados da produção, manejo e comercialização de açaí na safra e entressafra na Ilha do Combú e São Sebastião da Boa Vista a fim de compará-los.

\section{Fundamentação Teórica}

A atividade de extração do açaí é uma fonte de renda importante para as famílias interioranas, sendo dependentes de tal atividade, já que uma boa parcela de sua rende está diretamente ligada à venda do açaí. Um grande problema é a falta de planejamento fixo e estruturado para os períodos de baixa produtividade, também é importante salientar que tal produção fica à mercê das arvores disponíveis nos arredores da propriedade. (AZEVEDO, J. R.; KATO, O. R. 2007)

A produção de açaí está presente em mais de 14\% dos municípios do Pará, e a maior parte do fruto de açaí é proveniente de projetos de manejo em áreas de várzea, (TAVARES, G. S; HOMMA, A. K. O. 2015) sendo fonte de renda e subsistência para agricultores de pequeno porte e ribeirinhos. O mercado de açaí gera muitos lucros, e a produção precisa seguir um padrão de regularidade, principalmente no manejo, no entanto, a atividade extrativista reduz a produtividade significativamente no período de entressafra, o que leva essa população a recorrer a outras atividades que na falta de informação, acabam degradando seu ambiente. (XAVIER et al., 200-?)

Nas comunidades ribeirinhas onde há grande concentração de açaizais nativos, predomina a agricultura familiar, que se caracteriza pelo pequeno porte da propriedade, que em sua maioria no contexto analisado, tem a liderança masculina, onde as atividades alternativas de renda e subsistência são notórias. Além das atividades de extrativismo, criação e pesca, a comunidade ribeirinha subsiste por meio da renda de programas governamentais. (SOUSA, F. F; SILVA, C.M; BAROS, B. F. 2018).

Homma traz uma abordagem do potencial de crescimento do produto não só no âmbito nacional mas também internacional ,o que faz com que ele se torne um produto de grande importância econômica, houve também um grande avanço na tecnologia para o manejo do açaí seja na produção da polpa ou na criação de materiais para o transporte do caroço de açaí confeccionada com os talos de arumã, (rasas) movimentando a economia nas áreas ribeirinhas.( HOMMA, A. K. O, et al. 2006). 


\section{Metodologia}

Ao iniciar o projeto de pesquisa do presente artigo, foram realizadas pesquisas bibliográficas através do portal Capes com relação ao tema abordado para melhor compreender o assunto. Após a pesquisa bibliográfica, o grupo partiu para a pesquisa de campo. Uma das áreas de pesquisa foi a Ilha do Combú, município de Belém, a qual possui a produção do fruto do açaí e do palmito como principais atividades econômicas. Os deslocamentos ocorreram através da utilização de barcos motorizados e lancha. Para se chegar na Ilha, leva cerca de 15 minutos saindo de um dos portos de Belém. Outra área de pesquisa foi o município de São Sebastião da Boa Vista, Arquipélago do Marajó, pertencente à mesorregião do Marajó e à microrregião de Furos. A sede municipal apresenta as seguintes coordenadas geográficas: 01o 43’05” S “e 49o 31'45” W Gr. limita- se ao Norte com Anajás, a Leste com Muaná, Ao Sul com Limoeiro do Ajuru e a Oeste com Breves e Curralinho. (Prefeitura de São Sebastião da Boa Vista). A população do Município é cerca de 22.904 habitantes (IBGE,2010). O município fica a 124,6 km da capital, a viagem de barco leva aproximadamente 8 horas, de lancha, 5 horas.

A pesquisa foi realizada em meados do mês de julho de 2018, (início de safra em ambos os locais) tendo em vista alcançar o objetivo do trabalho foram realizadas visitas para se efetuar as entrevistas utilizando o método "face to face" e aplicação de questionários a 30 produtores de cada localidade, constituído de perguntas abertas e fechadas. O primeiro local visitado foi a Ilha do Combú, seguida de São Sebastião da Boa Vista. Nas visitas feitas aos locais e nas propriedades dos agricultores de açaí que ocorreu pelo período da manhã e tarde na ilha do Combú e em são Sebastião da boa vista nos rios Pracuúba e Guajará, observou-se a rotina dos coletores do fruto, os principais materiais que são utilizados na coleta e o processo de comercialização. Os dados obtidos foram organizados e posteriormente tabulados para obtenção de gráficos no programa Excel.

\section{Resultados e Discussão}

De modo geral, verificou-se que os entrevistados apresentam baixa escolaridade e subsiste da renda obtida com a produção de açaí, venda de excedentes de outras culturas e programas governamentais dentre outras atividades. Os coletores saem pela manhã a pé pela mata de açaizal ou de canoa pelos igarapés, munidos de botas ou sapatos, peconha, facão com rasas e/ou rasinhas (recipiente feito de fibras vegetais onde o fruto é armazenado). Na coleta pela manhã a debulha dos cachos é feita imediatamente na rasa. A coleta também pode ser feita 
pelo período da tarde onde os cachos são debulhados no dia seguinte para melhor conservação do fruto. $\mathrm{O}$ fruto depois de debulhado passa pelo processo de catação, é medido e colocado em um recipiente. Na Ilha do Combú é usado como medida a rasa (recipiente cilíndrico feito de fibras vegetais ou de plástico onde o fruto é armazenado) ou a basqueta (recipiente quadrado, plástico semelhantes a rasa) que comporta $28 \mathrm{~kg}$ do fruto, em São Sebastião da Boa Vista usase a rasinha ou lata que comporta $14 \mathrm{~kg}$. Os produtores entrevistados exercem a agricultura familiar, na tabela1 é mostrada a quantidade de pessoas que utiliza mão-de-obra exclusivamente familiar e as que contratam outras pessoas para auxiliar na colheita do fruto.

Tabela1- Mão-de-obra utilizada na colheita do fruto de açaí

\begin{tabular}{lcc}
\hline & Ilha do Combú & São Sebastião da Boa Vista \\
\hline Somente a família & $60 \%$ & $40 \%$ \\
Contrata pessoas as vezes & $30 \%$ & $40 \%$ \\
Contrata pessoas sempre & $10 \%$ & $20 \%$ \\
Fonte: Própria &
\end{tabular}

Na Ilha do Combú, a mão-de-obra familiar é predominante, e poucas famílias contratam outras pessoas efetivamente. Em São Sebastião da Boa Vista a mão-de-obra familiar e a contratação temporária estão em mesmo número, e a admissão de mão-de-obra efetiva é o dobro comparada a da Ilha do Combú. Essa ocorrência se dá por haver propriedades de tamanhos variados entre as quais, os membros da família não são suficientes para fazer a colheita principalmente na safra. Além de muitos produtores já não conseguirem fazer a escalada nas palmeiras para colher o fruto (fatores como idade e saúde física são determinantes) estes procuram outras pessoas para exercer a atividade.

Para Martinot, Pereira e Silva (2016, p.9), a agricultura familiar amazônica tradicional, singulariza-se por ser exercida essencialmente pela mão-de-obra familiar, sem intervenção nenhuma de outras pessoas para realizar a tarefa. $\mathrm{O}$ que vai de encontro com os resultados obtidos nos dois locais pesquisados, onde há contratação temporária de pessoal para colher o fruto de açaí, esse quadro de geração de emprego pela agricultura familiar é pouco relatado na literatura. A seguir, na tabela 2, é mostrada a relação da média de pessoas por família e a média das idades dos produtores nas duas localidades, a porcentagem de participantes por gênero e cor.

Tabela 2- Média de pessoas na família e idade. Percentagem de gênero e cor dos entrevistados

\begin{tabular}{lcc}
\hline & Ilha do Combú & São Sebastião da Boa Vista \\
\hline Pessoas na família & 4,2 & 4,6 \\
Idade: mulheres & 51 & 45
\end{tabular}




\begin{tabular}{lcc} 
Idade: homens & 33 & 45 \\
Masculino & $76,6 \%$ & $86,6 \%$ \\
Feminino & $23 \%$ & $13,3 \%$ \\
Preto & $26,6 \%$ & $13,3 \%$ \\
Pardo & $70 \%$ & $86,6 \%$ \\
Branco & $3,3 \%$ & $0,0 \%$ \\
\hline
\end{tabular}

Fonte Própria (2018)

Nos dois lugares o número de pessoas por família é aproximado, revelando as mudanças nas configurações das famílias interioranas ribeirinhas, onde outrora estas eram maiores e hoje essa parcela está reduzida. A média de idade das produtoras é maior que a dos produtores na Ilha do Combú, e as médias das idades em São Sebastião da Boa Vista é a mesma para homens e mulheres. Tanto a quantidade de membros quanto a idade média deles, sugere fatores relevantes para a escassez de mão-de- obra.

Nas duas localidades a maioria dos entrevistados eram homens, e esse número é ainda maior em São Sebastião da Boa Vista. Ainda em Sousa, Silva e Barros (2018, p. 4), onde no contexto analisado, tem a liderança masculina, condiz com os dados obtidos onde a presença masculina no cenário da produção de açaí está em maior quantidade, são eles em sua maioria que lideram as atividades de colheita. entretanto, as mulheres também atuam na produção do açaí, principalmente nas etapas de debulha e catação, além de auxiliar no processo de pesagem e comercialização. Tem-se com predomínio pessoas pardas, poucas e quase nenhuma branca nos respectivos locais. Mais de $70 \%$ da população ribeirinha visitada informou fazer cultivo de outras culturas como mostra a Figura 1, para subsistência e comercialização.

Figura 1- Gráfico das principais culturas cultivadas em São Sebastião da Boa Vista e Ilha do Combú.

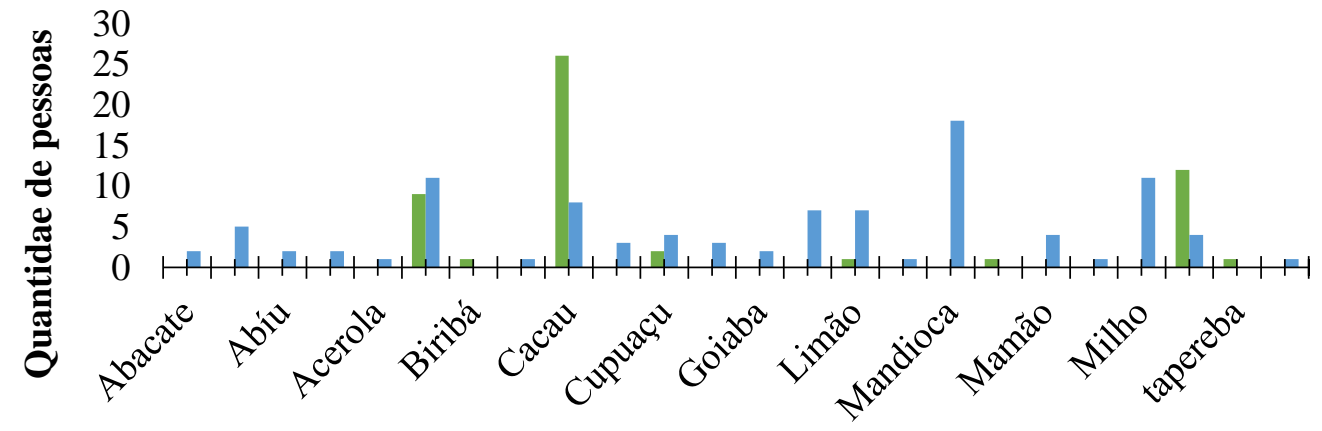

\section{Culturas cultivadas}

- Ilha do Combú $\quad$ São Sebastião da Boa vista

Fonte: Própria 
As principais culturas cultivadas na Ilha Combú são o cacau, com quase 100\% de presença na agricultura local, seguido da pupunha e banana, sendo o biribá, a manga e o taperebá recorrentes apenas no Combú. Em São Sebastião da Boa Vista as culturas mais prevalecentes são: mandioca, milho e banana, estando esta última presente em ambos os locais. A ocorrência principalmente de frutíferas se dá pela existência da roça (local onde se cultiva a mandioca) onde o espaço ao redor da cultura de mandioca possibilita o plantio de outros produtos e, da mesma forma, o consórcio de culturas.

Na região de São Sebastião da Boa Vista, em que 73,3\% da população entrevistada utiliza o cultivo de mandioca como forma de subsistência e renda complementar incorporada à produção de açaí e na Ilha do Combú onde a maioria dos indivíduos declarou cultivar outros produtos agregados ao cultivo de açaí, o trabalho de Costa, Piketty e Abramovay (2013, p. 108109 ), aponta que o uso convencional da terra necessita de um período de pousio para que haja recuperação do solo e manutenção dos níveis de produção, em contrapartida, os sistemas agroflorestais, permite que a mesma parcela de terra seja utilizada por longos períodos, e no caso dos sistemas agroflorestais e manejo de açaizal, são geradas rendas crescentes, com tendência a estabilização ao longo dos anos.

Dessa maneira, compreende-se que nos dois locais averiguados predomina o uso consciente da terra e o cultivo de diferentes lavouras, indicando a transição do monocultivo para uma agricultura alternativa, de acordo com as necessidades do mercado local e a viabilidade para o produtor, induzindo a uma rentabilidade que pode se estabilizar com o passar do tempo e gerar lucro o ano todo reduzindo as questões intrínsecas a entressafra do açaí. Entretanto, para que se alcance tal expectativa, são necessários incentivo governamental e tomada de atitude por parte dos produtores, por meio de assistência técnica e apoio financeiro.

No que corresponde ao manejo dos açaizais, há algumas semelhanças nos dois locais visitados, como a roçagem que implica em eliminar outras vegetações incluindo plantas daninhas, retirada de palmeiras muito altas ou improdutivas para a comercialização do palmito. É mais frequente na Ilha do Combú a replantio de mudas do que em São Sebastião da Boa Vista. A Tabela 3 exemplifica os tipos de manejo praticado pelos produtores de açaí das duas localidades.

Tabela 3- Manejos praticado nas duas localidades estudadas.

\begin{tabular}{lll}
\hline \multicolumn{2}{c}{ Ilha do Combú } & São Sebastião da Boa Vista \\
\hline Roçagem $100 \%$ & Roçagem & $100 \%$ \\
Retirada de palmito 100\% & Retirada de palmito 100\% &
\end{tabular}


O ato de manejar o açaizal é hábito na vivência dos agricultores de São Sebastião da Boa Vista e da Ilha do Combú, entretanto não se conhece a frequência com que são realizados tais manejos. Foi questionado nas entrevistas se já houve algum curso de manejo nas regiões, em São Sebastião da Boa Vista, 53,3 \% dos entrevistados afirmou ter ocorrido curso de manejo no local, no entanto, 46,6 \% deles confirmou ter participado. na Ilha do Combú 50\% do grupo declarou haver cursos de manejo, entretanto apenas $30 \%$ teve participação nos cursos.

Os dados confirmam que há pouco interesse por parte dos produtores em participar dos cursos ofertados, revelando que ainda há muito o que ser trabalhado nessas regiões em questão de levar informações e transmitir conhecimentos aos produtores. Aguiar, Martins, Simões, (2017) classificou os tipos de manejo de açaí em: manejo do agricultor, que consiste na roçagem do açaizal; em manejo de orientação técnica que abrange o plantio de mudas de açaí nativo e o desbaste de touceiras para a venda de palmito. Tais formas de manejo encontram-se presentes nas duas localidades visitadas. Visto que, o manejo de orientação técnica como o plantio de mudas de açaí é predominante na Ilha do Combú, comparado com São Sebastião da Boa Vista. A Figura 2 demonstra os tipos de comercialização realizadas nos dois lugares.

Figura 2- Gráfico do destino de comercialização do açaí na Ilha do Combú e São Sebastião da Boa Vista.

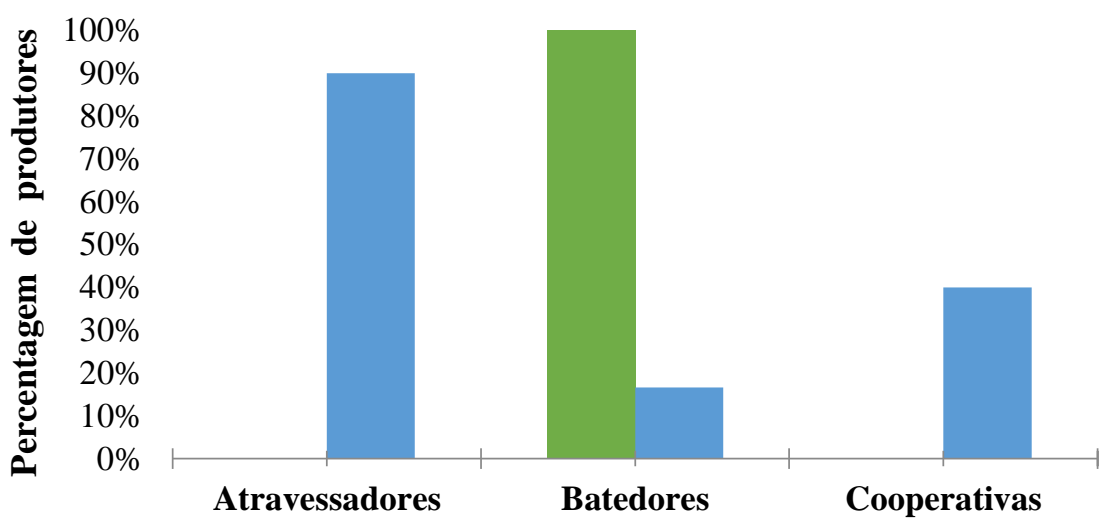

- Ilha do Combú - São Sebastião da Boa Vista

Fonte: Própria

Na Ilha do Combú, a comercialização é realizada diretamente entre produtores e batedores para restaurantes locais e em Belém especificamente no Porto da Palha, não havendo presença de atravessadores. Em contrapartida, nos rios Guajará e Pracuúba a comercialização é feita em sua maioria entre produtores e atravessadores, vende-se também para uma cooperativa existente nas proximidades e uma pequena parcela para batedores, ressaltando que apenas cinco 
dos trinta entrevistados em São Sebastiao da Boa Vista são integrantes da cooperativa local. Um dos colaboradores é presidente da cooperativa, denominada Cooperativa Agroextrativista da Veneza do Marajó- COOPAVEM, fundada em 2005 que conta atualmente com 42 cooperados, situada na Ilha Bala Vento, rio Pracuúba.

Em contaste com o trabalho de Nóbrega, Lima e Neto (2012), pode se atentar para o fato de que na região de Laranjal e Vitória do Jarí-AP, 51,8 \% dos entrevistados fazem parte de alguma cooperativa. Tal estatística difere dos locais pesquisados, onde constatou- se que somente $16 \%$ dos produtores faz parte de cooperativas. Pode se atribuir a esse fato, a falta de confiabilidade nas relações entre pessoas, falta de conhecimento acerca do cooperativismo ou até mesmo a falta de interesse dos produtores em desenvolver um produto com padrão de qualidade diferenciada.

A resposta para o preço do açaí na safra e entressafra varia de acordo com o produtor, a Figura 3 demonstra os preços mínimos, médio e máximo na Ilha do Combú que adota a medida da rasa ou basqueta de $28 \mathrm{~kg}$, e em São Sebastião da boa vista onde fenômeno da variação dos preços da mesma forma se repete.

Figura 3- Gráfico do valor de venda do açaí direto do produtor na safra e entressafra.

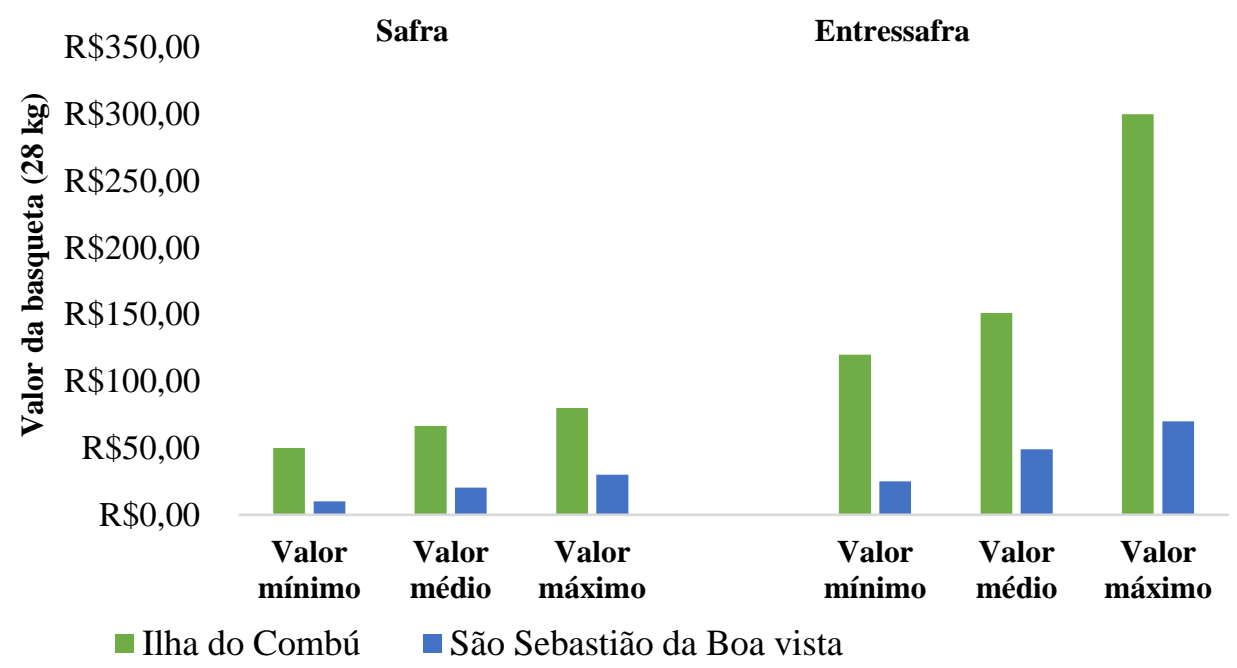

Fonte: Própria

O preço da rasa de açaí em ambos os locais apresenta diferença significativa de preço, observando que São Sebastião da Boa Vista comercializa o fruto do açaí por um preço inferior ao da Ilha do Combú. essa diferença se deve ao fato de nas localidades de São Sebastião da Boa Vista, existir a figura do atravessador. Para Silva, Barbosa e Albuquerque (2013) os atravessadores que interceptam a produção dos produtores, oferecem um retorno imediato (venda à vista), porém por um valor menor que o oferecido pela Cooperativa. Fenômeno este, 
observado na localidade de São Sebastião da Boa Vista, onde cerca de $90 \%$ dos produtores vendem o fruto para os atravessadores e somente $40 \%$ é destinado à cooperativa. Já na Ilha do Combú não há presença de atravessadores, e nem cooperativas de açaí, visto que a localidade é próxima da Feira do Porto da Palha e a maioria dos produtores possuem embarcação própria e o escoamento da produção que é realizado por eles mesmos.

Outra característica comum é alta do preço na entressafra, quando a demanda cai e a procura aumenta, o contrário se dá na safra quando a há oferta em abundância e o preço declina. Em Nogueira, Santana e Garcia (2013) um aumento do preço do produto leva a uma redução nas quantidades demandadas de açaí fruto, no Estado do Pará.

Por causa da flutuação do preço do açaí no mercado paraense, o Governo Federal, na safra de 2009/2010, incluiu o açaí na pauta da Política de Garantia de Preços Mínimos (PGPM), com a finalidade de garantir estabilidade à renda dos extrativistas, diante das oscilações dos preços de mercado. Assim, foi autorizado pelo Conselho Monetário, o reajuste no preço mínimo do açaí (fruto), para $\mathrm{R} \$ 0,83$ por kg do produto, a partir de 2011. Dessa forma, o produtor teria a garantia de receber o mínimo $\mathrm{R} \$ 11,62$ pela lata de $14 \mathrm{~kg}$ de açaí fruto (Brasil, 2011a). Caso o produtor comercialize $1 \mathrm{~kg}$ de açaí fruto por $\mathrm{R} \$ 0,50$, a Conab poderá complementar a renda produtor com a subvenção de $\mathrm{R} \$ 0,33$ (pois o preço mínimo é de $\mathrm{R} \$ 0,83$ ). Esta política de garantia de preços na comercialização do açaí, se for efetivamente implementada, deve funcionar como estímulo ao aumento da oferta do fruto no mercado paraense nos próximos anos. A quantidade de fruto de açaí produzida na safra e entressafra varia de acordo com a localidade. A Figura 4 apresenta as quantidades mínima, média e máxima dessa produção nos dois locais visitados.

Figura 4- Gráfico da quantidade de açaí produzida na safra e entressafra

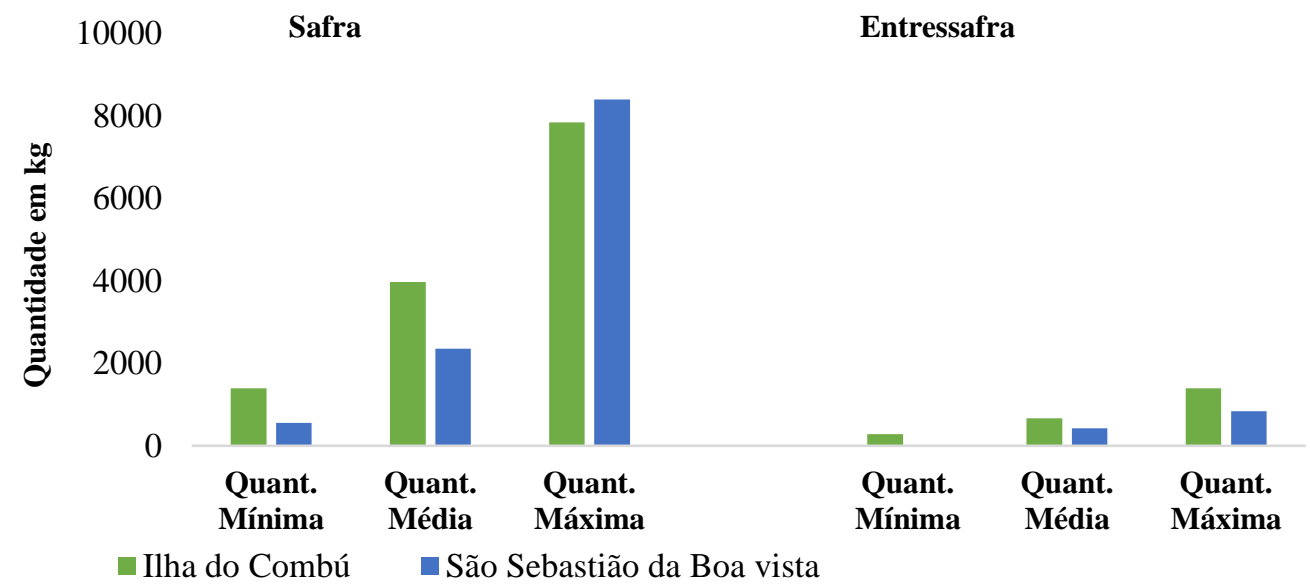

Fonte: Própria 
É evidente a alta produtividade na safra (período que vai de julho a dezembro) e o oposto entre os meses de janeiro a junho (período de entressafra) a partir dos dados coletados, a safra de São Sebastião da Boa Vista é mais produtiva, aproximando-se de 10 toneladas por produtor ao mês; já na entressafra, a Ilha do Combú se sobressai, alcançando aproximadamente 2 mil quilos ao mês. O manejo de replanta de mudas de açaí pode ser um dos agentes que ocasiona esse evento, como ja visto que 36,6 \% dos agricultores da Ilha do Combú faz plantio de mudas, enquanto que somente $10 \%$ dos produtores entrevistados em Sao Sebastiao da boa vista faz o plantio. As principais atividades que complementam a renda da população ribeirinha no Combú e nas localidades de São Sebastião são representadas pela tabela 4, uma delas, a criação de animais, -como galinha, porco, pato, peru, é recorrente nas duas zonas.

Tabela 4- atividades alternativas que são fontes renda para agricultores as da Ilha do Combú e São Sebastião.

\begin{tabular}{lrlc}
\hline Ilha do Combú em \% & & São Sebastião da Boa Vista em\% \\
\hline Palmito & 100 & Palmito & 100 \\
Cacau & 83,3 & Criação de animais & 90 \\
Pesca & 60 & Mandioca & 73,3 \\
Criação de animais & 50 & Pesca & 50 \\
Carpintaria & 10 & Milho & 40 \\
Trabalha em restaurante & 6,6 & Mercearia & 10 \\
\hline
\end{tabular}

Fonte: Própria

Observa-se importância da cultura de açaí, analisando-se que nos dois lugares o desbaste de palmeira altas ou improdutivas para a comercialização do palmito é unanime em ambos. Esta atividade é praticada tanto como atividade alternativa quanto forma de manejo. A totalidade do grupo entrevistado declarou vivenciar dificuldades no período da entressafra, a principal objeção por eles dita é de cunho econômico, a produção cai e da mesma forma, consequentemente, os lucros. A segunda é que alguns dos colaboradores afirmou que o açaí "falta na mesa", dá para o consumo, porém é reduzido.

As atividades alternativas de renda e subsistência são notórias. Além das atividades de extrativismo, criação e pesca, a comunidade ribeirinha subsiste por meio da renda de programas governamentais. Segundo Sousa, Silva e Barros. (2018, p 4), com exceção das atividades extrativistas, as demais atividades se repetem nas regiões da pesquisa, revelando uma constante no cotidiano dos ribeirinhos do estado do Pará. 


\section{Conclusões}

Com os resultados pode-se chegar, assim, a algumas conclusões; cada produtor tem seu meio de suprir a renda, sendo a produção de outras culturas algo presente em quase todas as entrevistas, já que, com a presença de outros produtos que tem seu período de safra coincidindo com o período de escassez do açaí, mantém a comercialização de diferentes produtos durante todo o ano, outro meio é a realização de outras atividades, notou-se também que mesmo com o cultivo de outras culturas a produção não e capaz de manter uma renda estável pois muitos alegam passar dificuldades financeiras neste período.

Não obstante, foi observado que a presença de um atravessador influencia diretamente na renda do produtor. A diferença de distância nos dois lugares em relação ao ponto de maior comercialização (Belém), influencia no preço do produtor, pois os custos com transporte são significativos. Portanto, faz-se necessário promover cursos de manejo aplicados e planejamento nessas localidades, já que com mais informações os produtores poderiam se estruturar e construir um plano de ação para os períodos de entressafra, assim, diminuindo sua dependência ao cultivo do açaí. Mesmo a pesquisa respondendo algumas perguntas e alcançando se objetivo, seria essencial que ocorressem outras pesquisas relacionadas a safra e entressafra, já que este artigo abrangeu apenas uma parte das mediações de Belém, algo que pode ser complementado com pesquisas futuras.

\section{Referências}

AGUIAR, A. G. R; MARTINS, P. F. da S; SIMÕES, A. V. Efeitos da intensidade do desbaste de estipes de açaizeiros (Euterpe oleracea Mart.) nativos na composição de parcelas de produção em várzea do estuário amazônico. Rev. Cienc. Agrar., v. 60, n. 4, p. 358-365, BelémPA, out./dez 2017.

AZEVEDO, J. R.; KATO, O. R. Sistema de Manejo de Açaizais Nativos Praticado por Ribeirinhos das Ilhas de Paquetá e Ilha Grande, Belém, Pará. In: VII Congresso Brasileiro De Sistemas De Produção, 2007, Fortaleza. ANAIS CD-ROM- Agricultura Familiar, Politicas Publicas e inclusão social. FORTALEZA: EMBRAPA,V. 1. 2007.

COSTA, R. C da; PIKETTY, M. G; ABRAMOVAY. Pagamentos por serviços ambientais, custos de oportunidade e transição para usos da terra alternativos: o caso de agricultores familiares do Nordeste paraense. Sustentabilidade em debate - Brasilia, v.4, n. 1, p. 99-116, jun. 2013.

HOMMA, et al. Açaí: novos desafios e tendências. Amazônia: Ciência \& Desenvolvimento, Belém, PA, v. 1, n. 2, p. 7-23, jan./jun. 2006. 
ILHA DO COMBÚ- Prefeitura de Belém. Disponível em https://www.belem.pa.gov.br/ilhadocombu > acesso em de agosto de 2018.

MARTINOT, J. F; PEREIRA, H. S; SILVA, S. C. P. Coletar ou Cultivar: as escolhas dos produtores de açaí-da-mata (Euterpe precatória) do Amazonas. Rev. de Economia e Sociologia Rural, Brasília Vol.55 n.4, p.751-766. Oct. /Dec. 2017.

NOGUEIRA, A. K. M; SANTANA A. C de; GARCIA, W. S. A dinâmica do mercado de açaí fruto no Estado do Pará: de 1994 a 2009. Rev. Ceres, vol. 60 no. 3 Viçosa May/June 2013.

NOGUEIRA, A. K. M; SANTANA, A. C; Benefícios socioeconômicos da adoção de novas tecnologias no cultivo do açaí no Estado do Pará. Rev. Ceres, UFLA: Viçosa-MG, Vol.63 n.1, p 1-7, jan./Feb. 2016.

NÓBREGA, J. A; LIMA, E. P; NETO, D. J. Diagnóstico sócio econômico dos produtores de açaí in natura, dos municípios de Laranjal do Jarí e Vitória do Jarí- AP. Rev. Verde, MossoróRN, Vol. 7, n. 4, p 23-29. 2013.

SILVA, A. R. P. ; BARBOSA, M. J. S.; ALBUQUERQUE, F. Sustentabilidade e empreendimentos econômicos solidários: análise da cooperativa dos fruticultores de Abaetetuba. Rev. de Administração Pública- RAP, Vol.47(5), p.1189 2013

PREFEITURA DE SÃO SEBASTIÃO DA BOA VISTA. Disponível em < http://www.pmssbv.pa.gov.br/>. Acesso em 14 de agosto de 2018.

RODRIGUES, P. L. et al. Dinâmica socioeconômica e organizacional em comunidade remanescente do quilombo Rio Gurupá, Marajó, Pará. Rev. Verde de Agroecologia e Desenvolvimento Sustentável. V.12, n 1, p. 105-116, 2017.

SILVA, L. R; et al. Agricultura Familiar Amazônica: Sistema De Produção - Ilha Compompema Abaetetuba - Pará. Rev. Fragmentos De Cultura, Goiânia, V.25, n 2, abril de 2015.

SOUSA, F. F; SILVA, C.M; BAROS, B. F. The (in)visible Market of miriti (mauritia flexuosa L.f.) fruits, the winter açaí, in Amazônian riverine communities of Abaetetuba, Northern Brazil. Global Ecology and Conservation, v. 14, p. e00393, 2018.

TAVARES, G. S; HOMMA, A. K. O. Comercialização do açaí no estado do Pará: Alguns comentários. Rev. Eumednet, Observatório de la economia Latinoamaricana. V. 2015, P. 1-13, 2015.

XAVIER, L. N. B; OLIVEIRA, E. A. de A. Q; OLIVEIRA, A. L. Extrativismo e manejo do açaí: atrativo amazônico favorecendo a economia regional. Rev. UNIVAP, v. 01, p. 1, 2009. 